\title{
Free Vibration Analysis of Cable Stayed-Bridge by Finite Element Method
}

\author{
Zaid S. Hammoudi ${ }^{1}$, Ali Laftah Abbas ${ }^{2}$, Haneen A. Mahmood ${ }^{3}$ \\ ${ }^{1,3}$ Department of Mechanical Engineering, College of Engineering University of Diyala \\ ${ }^{2}$ Department of Civil Engineering, College of Engineering, University of Diyala \\ enghaneenamer@gmail.com
}

\begin{abstract}
A delicate analysis of the natural frequencies and mode shapes of a cable stayed bridge is essential to the solution of its dynamic responses due to seismic, wind and traffic loads. In this paper, a bridge with geometry comparable to the Quincy Bayview Bridge was modelled in order to explore the significance of the three dimensional and free vibration analysis. This paper provides a detail of the bridge and the equivalent cross section of the three-dimensional finite element model implicating cables, the bridge deck and pylons as well as the boundary conditions and free vibration analysis by Ansys 15.0. The bridge was analyzed to free vibration to obtaine the natural frequency and mode shape. result of this paper present the natural frequencies and mode shapes of the bridge. The method of modelling cables is also studied. It is found that modelling cables as multi beam elements provides better results than using the traditional (and simpler) method of modeling them as single tensile elements.
\end{abstract}

Keywords: Cable-stayed Bridge; free vibration; finite element method

Paper History: (Received:18-4-2018; Accepted:10-102018)

\section{Introduction}

The cable stayed bridge has been developing rapidly since World War II, and becomes one of the most competitive types of bridges for main spans ranging from 300 to 600 meters. The results of some feasibility studies on building a cable stayed bridge with a main span over 1,000 meters motivated some huge bridge projects in Southeast Asia [1]. The behavior of cable stayed bridges has been studied by researchers to analyze their efficient use of materials and design. Some of the researchers analyzed the behavior of cable stayed bridges by using finite element method. Many types of modelling have been published in articles. Although two dimensional finite element models [2-4] have been widely studied, only the flexural mode has been considered. In order to estimate the importance of the lateral and torsional modes as well as their coupled modes for dynamic analysis, three-dimensional analysis may not be ignored for the longer span of cable-stayed bridges. The ASCE Committee on Cable-Stayed Bridge also indicated that with the increase of span length, the nonlinearities and three dimensional motion of the structure may no longer be ignored. For classical modal analysis, the natural frequencies of this model have an excellent agreement with Wilson's ambient test results. This model also can provide another types of dynamic analysis in the further. An accurate analysis of the natural frequencies and mode shapes of a cable stayed bridge is fundamental to the solution of its dynamic responses due to seismic, wind and traffic loads. The cables have been modelled as single truss elements in most previous dynamic analysis studies, such as those by [5-9]. Abdel-Ghaffar and Khalifa [9] investigated the effect of cable vibrations on the earthquake response of a cable stayed bridge using a three-dimensional finite element model in which each stay cable was divided into a string of small elements, The study also pointed out the inadequacy of using single truss elements for cable modelling and recommended the use of multiple elements for each cable. Subsequently, Tuladhar et al. [10] employed finite element method to study the influence of cable vibrations on seismic responses of cable-stayed bridges. They concentrated on the

effects of different mesh schemes, namely the singleelement model and the multiple-element model for each stay cable. They also concluded that the cable vibration effects are important for seismic response calculations, particularly when the cable fundamental frequencies are overlapping with the first few frequenciesof the bridge More recently, Caetano et al. [11,12].

Because of increasing in constructing cable stayed bridge in Iraq, In this paper, a cable-stayed bridge with the geometry similar to the Quincy Bayview Bridge has been considered. The modeling of this bridge consists three types of element which is different from some other three dimensional finite element models. Natural frequency and mode shapes of free vibration analysis of cable stayed bridge was indicating with two modeling methods. Result show that stay modeled as multi-beam element was

\section{Description of Cable Stayed Bridge}

Cable-stayed bridges can be divided into four primary parts, cables, pylons, the bridge deck and the boundary conditions. The Quincy Bayview Bridge consists of 56 cables in two planes along the bridge deck. The bridge is symmetrical about (y-axis) vertical axis. A mid span of bridge is $274 \mathrm{~m}$ fringed by two side span of $134 \mathrm{~m}$ in each. Towers of bridge have $53.7 \mathrm{~m}$ height above the deck and $17 \mathrm{~m}$ below the deck. Two $\mathrm{H}$ type pylons support the bridge deck and the cables. The lower end of the cables supports the bridge deck and the upper end of the cables 
connects at the top of pylon with fan type. The pylons are supported by the piers which are based under the water level. The ends of the bridge deck are supported by anchor piers.

\section{Finite Element Modeling of Cable Stayed Bridge.}

case study used in this paper is the Quincy Bayview Bridge crossing the Missippi river at0Quincy, Illinois, the bridge consist of two $\mathrm{H}$-shaped concrete towers, it a double plane semi-harp type cables, deck of bridge is composite concrete and two I -steel girders. The bridge description can be found in details in Wilson and Gravelle [13] for analysis purpose, the deck is divided into 30 elements. Bridge tower divided into 10 elements. Depending on the geometry, the towers are divided into three parts. The finite element model of the towers is shown in figure 1; cables are 28 cable distributing as a 14 cable for support the mid span and 7 support each side span. Cables are spaced at $2.75 \mathrm{~m} \mathrm{c} / \mathrm{c}$ at the top part of tower and their spacing is in equal. The relevant properties of the cables are given in Table (1). The finite element model of the Quincy Bayview Bridge has been modelled with three different types of elements, shell element, truss element and beam element. The cables are modelled as truss and beam element with and without modified modulus of elasticity. The pylons are modelled as beam elements. The bridge deck is modelled as a composite structure which consist shell and beam elements. Figure 1 represents the over view of the finite element model of Cable Stayed Bridge. Figure 2 shows three dimensional modelling of cable stayed bridge.

\section{Deck}

The floor of the bridge deck was modelled as four node shell elements. Each node of the element consists six degrees of freedom. There are translations in the $\mathrm{x}, \mathrm{y}$ and $\mathrm{z}$-direction as well as the rotations about the $\mathrm{x}, \mathrm{y}$, and $\mathrm{z}$-direction. The parapets, stringers as well as the composite girders have been modelled as three dimensional beam elements which also consist six degrees of freedom in translations and rotations. Referred to Figure 3, represents the finite element model of the typical cross section of the bridge deck. In order to accurately model the structure, the equivalent cross section of the bridge has been made.

\section{Tower}

Each pylon consist two columns and two struts which have been modelled as three-dimensional beam elements. The geometry of the pylons is divided as three different sections. In order to make more accurate model, three cross sections of the geometric property have been applied to the columns and one cross section of the geometric property has been applied to the struts.

\section{Cables}

The cables of Quincy Bayview Bridge have been modelled as truss elements. The single truss element is tension-only member. The elements consist three degrees of freedom of translations in $\mathrm{x}, \mathrm{y}$ and $\mathrm{z}$-direction. Cables modelled as 6-beam 181 element with pre-stressed cables. Cross section area of link cable shown in Table 1, in case beam cable with area as the same of link cable area.

Table1. Properties of the stay cables of cable-stayed bridge[14].

\begin{tabular}{|l|c|c|c|}
\hline Cables number & Cross-sectional area $\left(\mathrm{m}^{2}\right)$ & Young's modulus $(\mathrm{MPa})$ & Cable weight $(\mathrm{N} / \mathrm{m})$ \\
\hline $\mathbf{1}$ & 0.018 & 205000 & 1765.80 \\
\hline $\mathbf{2}$ & 0.0135 & 205000 & 1324.35 \\
\hline $\mathbf{3}$ & 0.0107 & 205000 & 1049.67 \\
\hline $\mathbf{4}$ & 0.007 & 205000 & 686.70 \\
\hline & & & \\
\hline
\end{tabular}

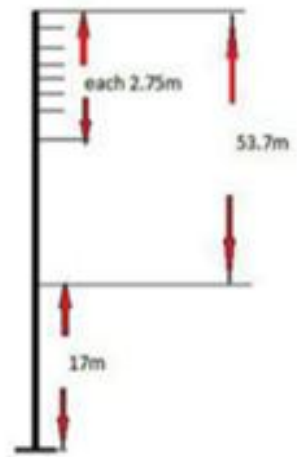

(a) Finite Element of Tower

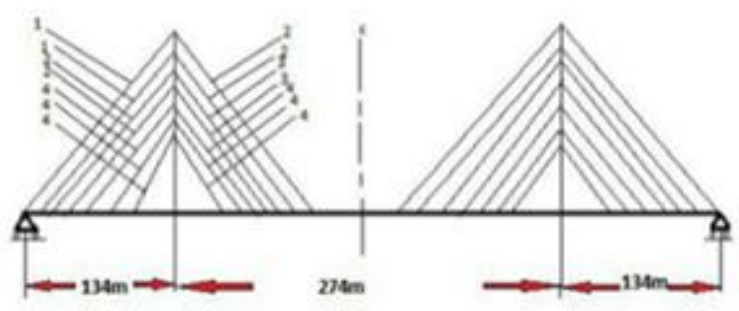

(b) Model of Bridge

Figure1. Details of cable stayed bridge[14] 


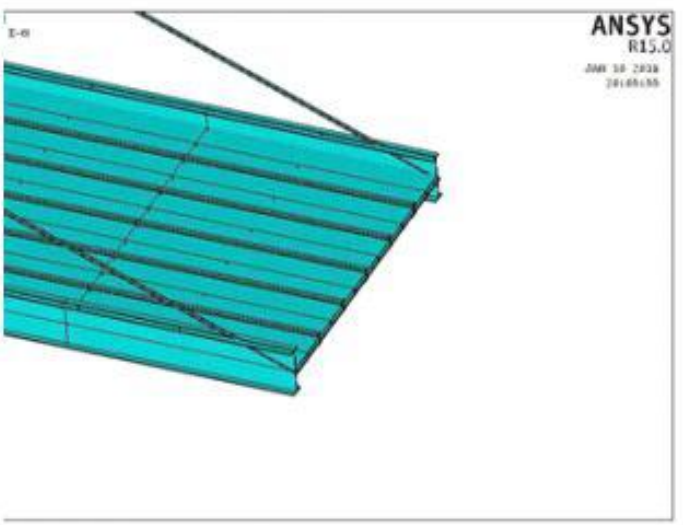

(a) Three dimensional modeling of deck

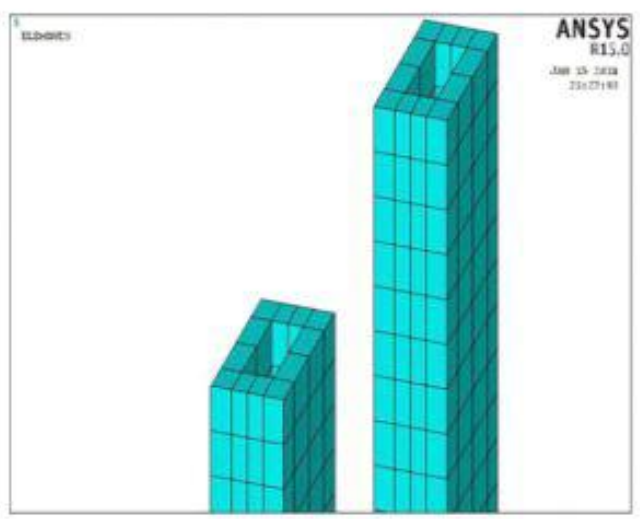

(b)Three Dimensional Modelling of Tower

Figure2.finite element modelling of deck and tower

\section{Boundary condition}

The boundary conditions of finite element model are always very hard to model exactly the same as those of the real structures. The estimated boundary conditions must be taken in this project. The connection between the piers and the pylons has been considered as fixed connection. The connection between the cables and the bridge deck has also been considered to be fixed. Based on the Engineering Drawing of Quincy Bayview Bridgeg, the connection between the bridge deck and the cables is allowed to rotate in a certain condition. The three dimensional truss elements don't take the rotational resistances. Therefore, the difference between the fixed connection and the pinned connection can be ignored for modal analysis of this type structure.

The base of the towers (at connection with ground) is considered as fixed in all directions. Earthquakes are entered as acceleration to all nodes of the bridge. Figure $2 \mathrm{~b}$ shows boundary condition of cable-stayed bridge with cables modelled as 6-beam element. Figure 2c shows boundary condition of cable-stayed bridge with cables modelled as single link element.

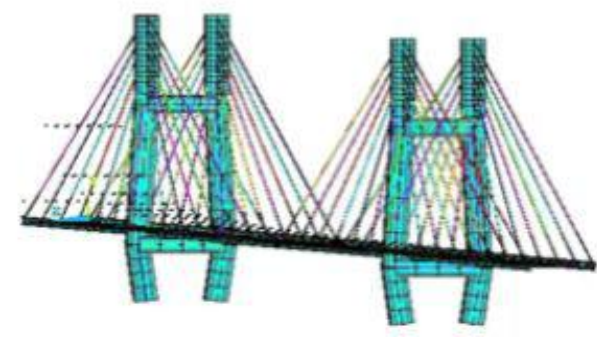

(a) Three dimensional modeling of cable-stayed bridge

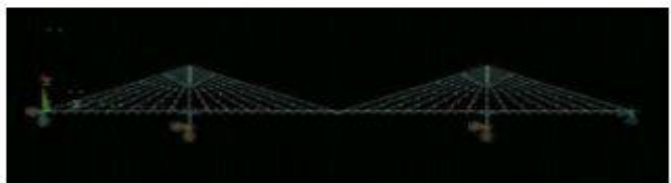

(b) Boundary condition of cable stayed bridge with cables cables modeled as 6-beam element

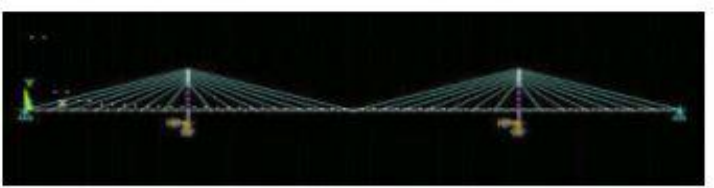

(c)Boundary condition of cable-stayed bridge with modeled as single link element.

Figure3. Three-dimension modeling and boundary condition of cable stayed bridge

\section{Result and Discussion}

Free vibration analysis of a cable stayed bridge is presented in this paper. The suspension of the bridge by tension cables adds a significant complication to the analysis of vibration. To verify the findings of current research, the results are compared to these presented in Reference [14]. Table (2) shows results of natural 
frequencies and mode shapes of this reference. It can be seen that results are in good agreement although rather different modeling techniques used. So in this paper, two basic methods of modelling stay cables are used. First method is cable-stayed bridge with cables modelled as single link element, second method is cable-stayed bridge with cables modelled as 6-beam element, and noted the difference between them and whichever the best is. Free vibration analysis result of first method is shown in Figure (4), first column shows the natural frequency of bridge with first method. Figure (5) shows result of free vibration analysis of cable stayed bride with cables modelled as multi beam element. There are many types of mode shapes appear in second method, but it is missing in free vibration analysis of bridge with cables as single link element. The natural frequencies obtained from multi beam element modelling of stay cables (second method of modelling) are compared with result of single link element in Figure (4). It is observed that the same coupled modes as those obtained from first method of modelling cables as link element are found from second method although their values are slightly deferent. In general, several mode shapes was missing in in bridge with cables modelled as link element, but are appear in multi- beam element cables. Cable stayed bridge with cables modelled as single link element is make cables as a rigid element with tension only, this method is simple but it is inadequate for the accurate dynamic analysis of a cablestayed bridge because it essentially precludes the transverse cable vibrations. In other words, the resulting mode shapes account for the vibrating deck and towers only, while neglecting the dynamic interaction among the cables, the deck and the towers. Multi-beam element modelling of stay cables allow to cables to be in tension a compression because their multi-element.

Table 2. natural frequencies and mode shapes of current research and of reference [14]

\begin{tabular}{|c|c|c|c|}
\hline Mode shape & Frequency in reference $[14](\mathrm{Hz})$ & $\begin{array}{l}\text { Frequency with link } \\
\text { cable bridge }(\mathrm{Hz})\end{array}$ & Frequency with beam cable bridge (Hz) \\
\hline 1 & 0.3501 & 0.37802 & 0.37058 \\
\hline 2 & 0.5197 & 0.44806 & 0.45148 \\
\hline 3 & 0.7611 & 0.73862 & 0.73589 \\
\hline 4 & 0.8178 & 0.802985 & 0.84188 \\
\hline 5 & 0.8964 & 0.84615 & 0.96220 \\
\hline 6 & 0.9102 & 0.97317 & \\
\hline
\end{tabular}

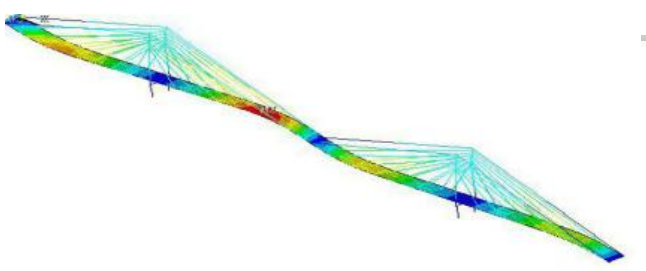

Flexural mode shape $(0.37802 \mathrm{~Hz})$

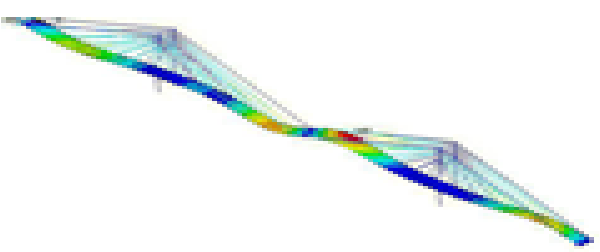

Flexural mode shape $(0.73862 \mathrm{~Hz})$

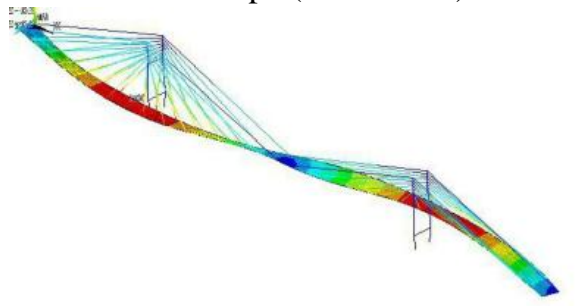

Torsional with lateral mode shape $(0.44806 \mathrm{~Hz})$

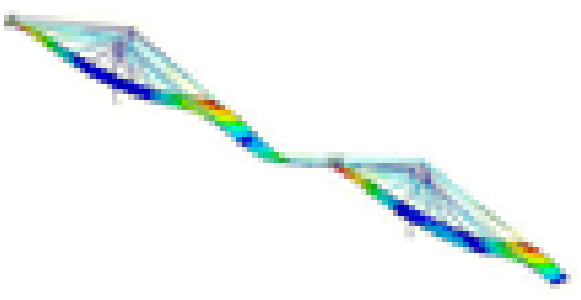

Flexural mode shape $(0.802985 \mathrm{~Hz})$

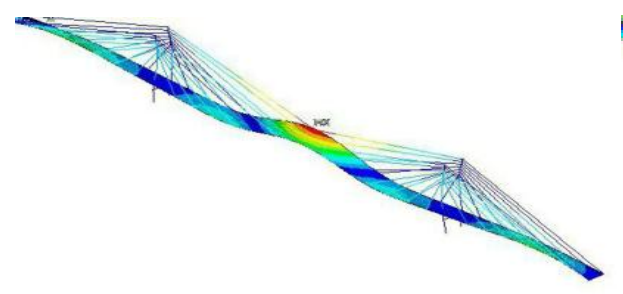

Lateral with torsional mode shape $(0.64556 \mathrm{~Hz})$

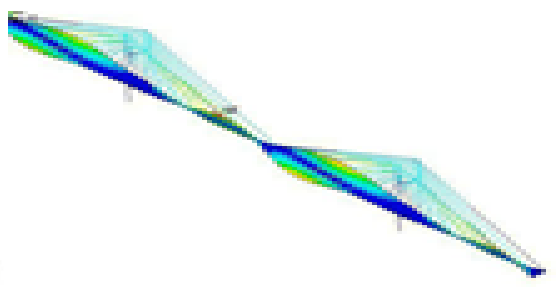

Torsional mode shape $(0.84615 \mathrm{~Hz})$ 


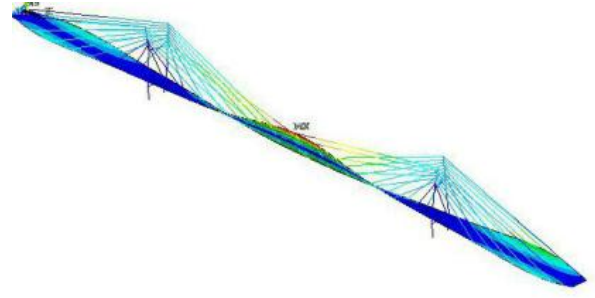

Lateral with Torsional $(0.65607 \mathrm{~Hz})$

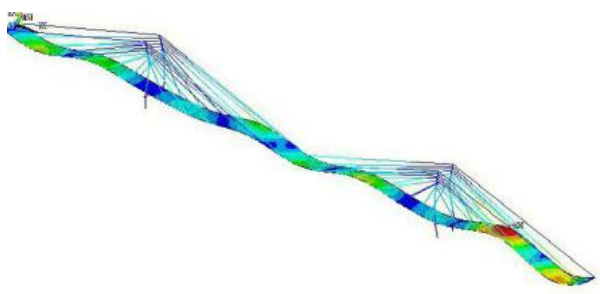

Flexural mode shape $(0.97317 \mathrm{~Hz})$

Figur 4. The natural frequencies of cable stayed bridge with cables modeled as multi-beam element

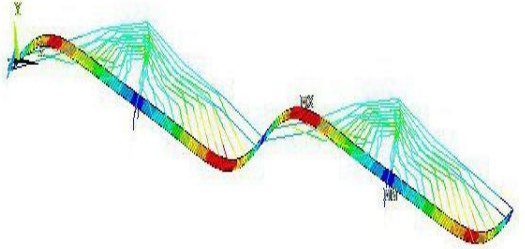

Flexural mode shape $(0.37058 \mathrm{~Hz})$

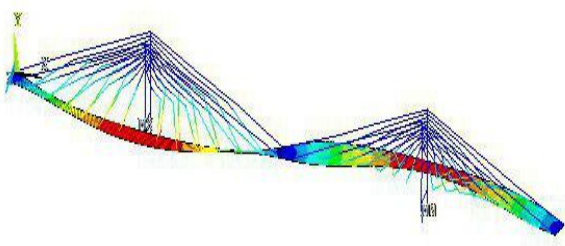

Torsional with lateral mode shape $(0.45148 \mathrm{~Hz}) \quad$ Torsional mode shape $(0.84188 \mathrm{~Hz})$

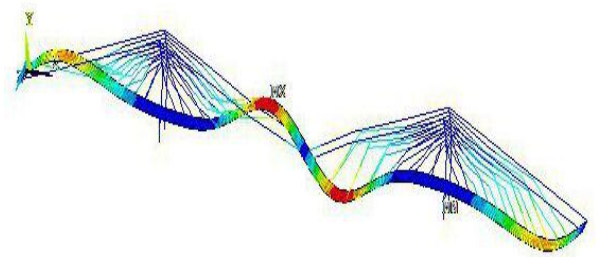

Flexural mode shape $(0.73862 \mathrm{~Hz})$

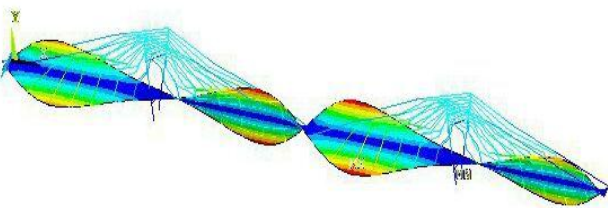

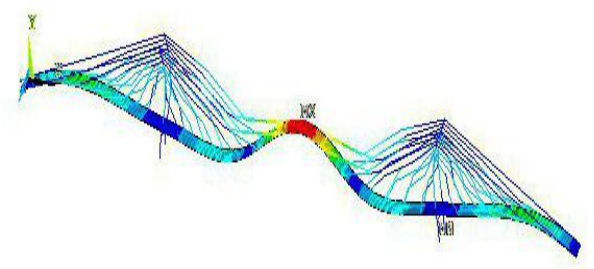

Flexural mode shape $(0.64547 \mathrm{~Hz})$

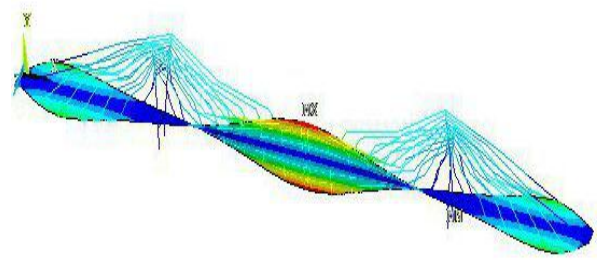

Torsional with Lateral $(0.65237 \mathrm{~Hz})$

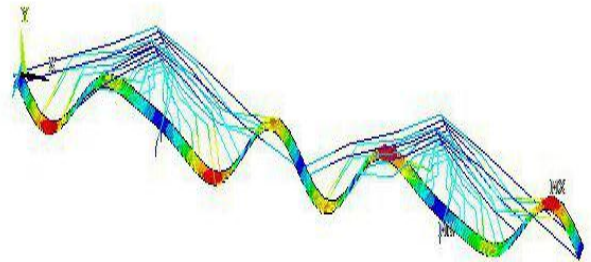

Flexural mode shape $(0.87061 \mathrm{~Hz})$

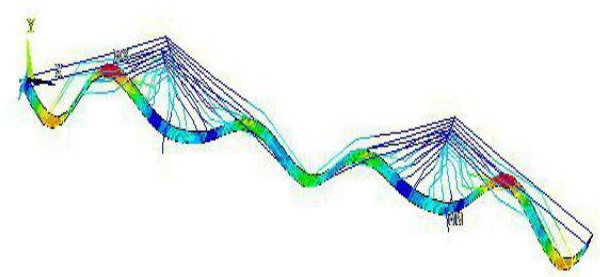

Flexural mode shape $(0.96220 \mathrm{~Hz})$

Figur 5. The natural frequencies of cable stayed bridge with cables modeled as single-link element 


\section{Conclusion}

In this paper, free vibration analysis of cable-stayed bridge has been considered in two method of modelling stays cables of cable-stayed bridge depending on the number of Element in the cables. The result indicated that the multi-element method of modelling (cable divided into 6-beam element) was difficult method and more accuracy than the first method (single-element methode). In addition, multi types of mode shapes appears in multi beam element of modelling cables, but these mode shapes was missing in first method of modelling cables (single link element).

\section{Acknowledgment:}

Authors wishing to acknowledge assistance and encouragement from colleagues in the mechanical Engineering Department, collage of engineering, University of Diayla, Iraq,

\section{References:}

[1].HUA, C.-H. \& WANG, Y.-C. Three-Dimensional Modeling of a Cable-Stayed Bridge for Dynamic Analysis. Proceedings-SPIE the International Society for Optical Engineering, 1996. SPIE International Society for Optical, 1565-1571.

[2].ASCE Committee "Guidelines for the Designof Cable-Stayed Bridges”, ASCE, 1992.

[3].Ermopoulos, J. CH., Vlahinos, AS., and Wang, Yang-Cheng "Stability Analysis of Cable-Stayed Bridges", International Journal of Computers \& Structures, Vol. 22 No.12, pp.1083-1089 June 1993.

[4].Vlahinos and Yang-Cheng Wang, "Effect of Supporting Conditions on the Critical Loads of CableStayed Bridges", the Proceedings of the Twenty-Third Midwesten MechanicsConference, Oct.,1993, pp.190192.

[5].N.F. Morris Dynamic analysis of cable-stiffened structures Journal of the Structural Division ASCE, 100 (5) (1974), pp. 971-981

[6].J.F. Fleming, E.A. Egeseli Dynamic behavior of a cable-stayed bridge Earthquake Engineering and Structural Dynamics, 8 (1) (1980), pp. 1-16

[7]. T.L. Wang, D. Huang Cable-stayed bridge vibration due to road surface roughness Journal of Structural Engineering ASCE, 118 (5) (1991), pp. 1354-1374

[8].A.M. Abdel-Ghaffar, A.S. Nazmy 3-D nonlinear seismic behavior of cable-stayed bridges Journal of
Structural Engineering ASCE, 117 (11) (1991),pp.34563476

[9].Wilson JC, Gravelle W. Modeling of a cable-stayed bridge for dynamic analysis. Earthquake Engng Struct Dynam 1991;20:707-21.

[10]. J.C. Wilson, W. Gravelle Modelling of a cablestayed bridge for dynamic analysis Earthquake Engineering and Structural Dynamics, 20 (1991), pp. 707-721

[11]. A.M. Abdel-Ghaffar, M.A. Khalifa Importance of cable vibration in dynamics of cable-stayed bridges Journal of Engineering Mechanics ASCE, 117 (11) (1991), pp. 2571-2589

[12]. R. Tuladhar, W.H. Dilger, M.M. Elbadry Influence of cable vibration on seismic response of cable-stayed bridges Canadian Journal of Civil Engineering, 22 (1995), pp. 1001-1020

[13]. E. Caetano, A. Cunha, C. Taylor, Dynamic cable-deck interaction in cable-stayed bridges, in: Proceedings of the 15th International Modal Analysis Conference, Orlando, 1997, pp. 301-307

[14]. Hua, C. H., \& Wang, Y. C. (1996). ThreeDimensional Modeling of a Cable-Stayed Bridge for Dynamic Analysis. In Proceedings of The 14th International Modal Analysis Conference (Vol. 2768, p. 1565). 